\title{
REFLEXÕES SOBRE A TEORIA DOS JOGOS NA MEDIAÇÃO
}

\section{REFLECTIONS ON THE GAME THEORY IN MEDIATION}

\author{
ALINE TRINDADE do NASCIMENTO \\ Bolsista da CAPES. Mestranda em Direito na Universidade de Passo Fundo. \\ Especialista em Direito e Processo do Trabalho pela Faculdade Anhanguera-Uniderp. \\ alineh.nascimento@hotmail.com
}

\section{RESUMO}

O presente texto busca abordar as contribuições da teoria dos jogos para a mediação. Para tanto, na primeira parte deste artigo é feita uma abordagem acerca da mediação, sua finalidade, seus princípios bem como sobre o papel do mediador durante esse procedimento. Já na segunda parte busca-se compreender a teorias dos jogos, sua dinâmica e funcionamento, a importância do equilíbrio de Nash para essa teoria e, sobretudo, como ela pode ser utilizada durante as sessões de mediação. Na elaboração deste artigo, utilizou-se o método de abordagem dialético, como técnicas específicas, foram empregadas pesquisas bibliográficas. Por meio deste estudo, foi possível verificar no que consistem a mediação e a teoria dos jogos, além disso, demonstrou-se como a teoria dos jogos pode auxiliar para a prática da mediação.

Palavras-chave: Equilíbrio de Nash; Mediação; Teoria dos jogos.

\begin{abstract}
This paper seeks to approach the contributions of the game theory for mediation. For this purpose, in the first part of this research an approach about mediation is made, including its purpose, its principles and the mediator's role during this procedure. In the second part, this study seeks to understand the game theory, its dynamic and functioning, the importance of Nash equilibrium for this theory, and especially how it can be used during mediation sessions. To elaborate this paper, the dialectical method of approach was used, such as literature review. Through this study, it was possible to verify what mediation and the game theory are, moreover, it was demonstrated how the game theory can assist the practice of mediation.
\end{abstract}

Keywords: Nash equilibrium; mediation; game theory.

\section{SUMÁRIO}

INTRODUÇAO; 1 A MEDIAÇÃO; 2 A TEORIA DOS JOGOS NA MEDIAÇÃO; CONCLUSÃO; REFERÊNCIAS. 


\section{INTRODUÇÃO}

A mediação é objeto de discussões e debates no meio jurídico na atualidade, sobretudo, após sua inclusão no Novo Código de Processo Civil (Lei n 13.105/2015). No entanto, ainda há muito a se estudar e amadurecer sobre esse importante método de tratamento de conflitos, desse modo, poder-se-á compreender e aplicar as principais técnicas de seu procedimento.

Nesse sentido, estudar a teoria dos jogos pode se revelar interessante. 0 conceito pertencente ao ramo da matemática aplicada e da economia e tem por objetivo estudar os comportamentos estratégicos, principalmente, por meio da percepção da estratégia dominante e da identificação do equilíbrio de Nash.

Em um primeiro momento, pode-se pensar que a dinâmica da teoria dos jogos pode estar distante do direito. Entretanto, essa instigante teoria pode contribuir muito para aqueles que estão empenhados em estudar a dinâmica das relações sociais, tal como se busca na mediação. A teoria dos jogos pode auxiliar na compreensão e na realização das sessões de mediação, pois ajuda a entender o comportamento humano.

Sabe-se que o direito é uma ciência que visa regular a vida em sociedade. Situado dentro de um espaço social, tem como matéria-prima o fenômeno jurídico. É fruto da convivência, da transformação e da interação pessoal, de modo que busca estabelecer padrões comportamentais de acordo com a dinâmica social, razão pela qual não pode ser visto como algo absoluto, estático, dogmático.

O direito tem como objetivo modelar o comportamento das pessoas a fim de equilibrar as relações sociais e amenizar as injustiças. No entanto, é incapaz de prever todas as consequências que as regras jurídicas poderão apresentar para a sociedade, é por isso que a economia, principalmente a análise econômica do direito, pode colaborar nessa leitura.

Dessa forma, com o intuito de realizar um estudo interdisciplinar e dialético, na primeira parte deste trabalho, o objetivo é abordar a finalidade da mediação, seus princípios e o papel do mediador nesse procedimento. Já na segunda metade, pretende-se estudar a teoria dos jogos, explicar as estratégias "ótima” e "dominante", o equilíbrio de Nash bem como as estratégias puras e mistas, relacionando tais conceitos com a mediação. 


\section{A MEDIAÇÃO}

A mediação consiste em um meio complementar de solução de conflitos, que busca reestabelecer o diálogo entre os envolvidos em um problema, procura tratar o conflito, contribuindo para sua resolução pacífica. Consiste-se em um mecanismo consensual, no qual "as partes apropriam-se do poder de gerir seus conflitos, diferentemente da Jurisdição estatal tradicional na qual este poder é delegado aos profissionais do direito". ${ }^{1}$

Ainda, segundo Spengler: "a mediação, como ética da alteridade, reivindica a recuperação do respeito e do reconhecimento da integridade e da totalidade dos espaços de privacidade do outro, repudiando o mínimo de movimento invasor e dominador". 2

Seu objetivo não é apenas o acordo, mas restabelecer a comunicação, aproximar, possibilitar interação entre os envolvidos. A proposta desse instituto pode se revelar transformadora, pois ela não busca a decisão de um terceiro, mas, a resolução pelas próprias partes, que recebem o auxílio do mediador para administrar o conflito. Não se preocupa com o litígio (com a verdade formal contida nos autos), mas em ajudar as partes a redimensionar o problema. $^{3}$

Muller vê a mediação como um meio que:

[...] visa conduzir os dois protagonistas a passar da adversidade à conversação [...], ou seja, levá-los a voltar-se um para o outro para conversar, compreenderse e, se possível, chegar a um acordo que abra caminho à reconciliação. 0 mediador empenha-se para ser um 'terceiro que pacifica'. Por seu intermédio, tenta romper a relação 'binária' de dois adversários que se agridem surda e cegamente, a fim de estabelecer uma relação 'ternária' por meio da qual poderão comunicar-se pela intervenção de um intermediário. ${ }^{4}$

A mediação consiste em um procedimento democrático, pois rompe com o dogma imposto pelo conjunto normativo. Também é democrática quanto ao fundamento da relação de um com o outro, pois acolhe a desordem do conflito. Ela aposta em uma matriz autônoma,

\footnotetext{
1 SENGLER, Fabiana Marion; SPENGLER NETO, Theobaldo. A possibilidade do tratamento de conflitos no âmbito do Judiciário por meio da teoria dos jogos. Desenvolvimento em Questão, Ijuí: Editora Unijuí, v. 7, 2009, p. 132.

${ }^{2}$ SPENGLER, Fabiana Marion. Retalhos da mediação. Santa Cruz do Sul: Esserenel Mondo, 2014, p. 45.

${ }^{3}$ WARAT, Luis Alberto. Surfando na pororoca: o ofício do mediador. Florianópolis: Fundação Boieteux, 2004.v. III, p. 60-63.

${ }^{4}$ MULLER, Jean-Marie. 0 princípio da não-violência: uma trajetória filosófica. Tradução Inês Polegato. São Paulo: Palas Athena, 2007, p. 151.
} 
cidadã e democrática, ultrapassando aquela concepção baseada no litígio e na cientificidade do descobrimento da verdade. ${ }^{5}$

Permite que a concepção de justiça seja concebida sob outras perspectivas. A cultura de esperar que o juiz "diga o direito", como aquela figura que determina o que é justo, passa a ser repensada. A mediação possibilita que a ideia de justiça seja construída pelos próprios envolvidos em um litígio. Por intermédio do reestabelecimento do diálogo, a mediação possibilita o tratamento dialético do conflito, o que geralmente acarreta uma significativa percepção de justiça entre os mediandos. Em vista disso, Spengler afirma:

O desencontro de posicionamentos vertidos de uma situação conflituosa, a figura do mediador enquanto terceiro intermediário do conflito, a inexistência de previsibilidade e certeza jurídicas são vistos como limitadores da mediação. Essa visão nasce da necessidade de ordem estabelecida pelas prerrogativas de um sistema jurisdicional cuja racionalidade vê na autoridade estatal o direito de dizer quem ganha e quem perde o litígio. 0 que se observa é a necessidade de limitar a violência e a desordem através do monopólio dessa própria violência por parte do Estado. ${ }^{6}$

Nesse sentido, é interessante ressaltar os princípios que norteiam a mediação, que são: princípio da independência, da imparcialidade, da autonomia, da confidencialidade, da decisão informada, da informalidade e da oralidade. ${ }^{7}$

O princípio da independência concede a prerrogativa de recusar, suspender ou interromper a sessão naquelas situações em que não houver condições necessárias para o bom desenvolvimento dos procedimentos da mediação.

O princípio da imparcialidade confere ao mediador o dever de agir com imparcialidade durante as sessões, de modo que the é vedado sugerir ou impor qualquer solução aos mediandos. Não é demais ressaltar que a função do mediador é possibilitar que os participantes da mediação conversem e encontrem uma solução em conjunto, por isso a necessidade de uma conduta imparcial da parte desse terceiro, sendo-lhe vedado beneficiar alguma das partes. Nesse sentido:

\footnotetext{
${ }^{5}$ SPENGLER, Fabiana Marion. Retalhos da mediação. Santa Cruz do Sul: Esserenel Mondo, 2014, p. 49-50. ${ }^{6}$ Ibid., p. 48.

${ }^{7}$ BRASIL. Lei no 13.105 de 16 de março de 2015. Dispõe sobre 0 Código de Processo Civil. In: Diário Oficial da República Federativa do Brasil, Brasília, DF, 17 mar. 2015. Disponível em: < http://www.planalto.gov.br/ccivil_03/_ato2015-2018/2015/lei//13105.htm> Acesso em: 26 abr. 2016, art. 166.
} 
A mediação de conflitos, com seus valores, técnicas e habilidades, supõe princípios voltados ao asseguramento da efetiva facilitação do diálogo, em condições de igualdade de oportunidades e liberdade igual, com vistas à compreensão e ao alcance dessa justiça do caso concreto. ${ }^{8}$

O princípio da autonomia assegura que a tomada das decisões deve partir exclusivamente dos envolvidos, desse modo, são eles que devem buscar encontrar a melhor solução para o problema. Pode-se perceber que os princípios da imparcialidade e da autonomia se complementam.

Já o princípio da confidencialidade (também conhecido como princípio da privacidade) resguarda o sigilo da mediação. Assegura-se com esse princípio o dever do mediador de informar às partes que nenhum assunto tratado nas seções de mediações será público. A finalidade desse princípio é deixar os mediandos confortáveis de modo a possibilitar o reestabelecimento da confiança e da comunicação.

O princípio da decisão informada garante aos mediandos a tomada de consciência de seus direitos bem como resguarda a realidade fática em que se encontram como uma condição de legitimidade, propiciando, assim, que resolvam o conflito e formalizem um acordo.

Por princípio da informalidade entende-se que a mediação é um processo informal, de modo que inexistem normas formais e estáticas que norteiem o procedimento, há apenas orientações e preceitos que devem ser observados. Esse princípio permite a análise do caso concreto por meio de um estudo detalhado, o que, geralmente, revela-se positivo ao procedimento.

Além disso, desse último princípio (o da informalidade) deriva o princípio da oralidade, que estabelece que os atos ocorridos durante as sessões devem ser orais, isto porque um dos principais objetivos da mediação é o diálogo. Ademais, esse princípio visa também assegurar o sigilo da mediação, haja vista que há lavratura de ata da sessão, na qual deve constar apenas os termos do eventual/possível acordo firmado entre os mediandos, qualquer outra informação envolvendo as partes deve ser somente do conhecimento daqueles que participam da sessão. Nesse sentido:

0 procedimento de mediação caracteriza-se, ainda, pela oralidade, uma vez que se trata de um processo informal no qual as partes têm a oportunidade de debater os problemas que thes envolvem, visando encontrar possibilidades. 0 fato é que essa oralidade serve também para reaproximar os conflitantes, visto que o instituto da mediação, ao contrário da jurisdição tradicional, busca o

\footnotetext{
${ }^{8}$ BRASIL. Ministério da Justiça. Escola Nacional de Mediação e Conciliação. Manual de mediação de conflito para advogados: escrito por advogados. Brasília: Ministério da Justiça, 2014, p. 51-52.
} 
tratamento das pendências através do debate e do consenso, tendo como objetivo final a restauração das relações entre os envolvidos. ${ }^{9}$

Convém destacar que o novo Código de Processo Civil deixou de incluir o princípio da voluntariedade, que geralmente é citado em pesquisas e publicações que tratam do tema mediação. Esse dito princípio é importante porque garante a não obrigatoriedade da mediação, assegura a liberdade de escolha dos participantes, propicia aos envolvidos o poder de escolher o método de mediação que melhor thes convier, estabelece a liberdade ao optar pela mediação. Muitos pesquisadores entendem que qualquer ato coercitivo é incompatível com a mediação.

Ocorre que o novo código estabelece a obrigatoriedade de uma audiência inicial de conciliação e mediação, que será dispensada apenas quando ambos os envolvidos manifestarem desinteresse, ${ }^{10}$ em outras palavras, caso um dos envolvidos no conflito permaneça em silêncio ou manifeste interesse nessa audiência ela ocorrerá, mesmo que a outra parte evidencie seu desinteresse. Ademais, a ausência injustificada de uma das partes, no caso de haver pelo menos um interessado na audiência, será considerada como ato atentatório à justiça. ${ }^{11}$ Tal situação tem gerado muito debate e discussão, haja vista que por meio desse novo dispositivo legal, a mediação passa a ter caráter mandatário em algumas situações, o que é contrario ao princípio da voluntariedade.

Também é importante ressaltar que a mediação conta com o apoio de um terceiro, denominado mediador, que tem como atribuição propiciar os meios capazes de possibilitar o diálogo entre os mediandos. Isto porque a mediação consiste-se em um procedimento por meio do qual os envolvidos são estimulados a expressar as suas posições, interesses, necessidades, sentimentos, questões, opções, bem como formalizar as decisões tomadas consensualmente. ${ }^{12}$

A função do mediador é propiciar o equilíbrio das relações, gerir o conflito. Cabe a ele ajudar na construção do diálogo por meio da utilização dos princípios e procedimentos durante as sessões de mediação. Dessa forma, o mediador não pode ocupar um lugar de superioridade em relação aos mediandos, ele deve situar-se entre os participantes (no meio), por isso a sua denominação, pois busca mediar, equilibrar e, assim, reestabelecer os vínculos que, até então, estavam rompidos.

\footnotetext{
${ }^{9}$ SPENGLER, Fabiana Marion. Retalhos da mediação. Santa Cruz do Sul: Esserenel Mondo, 2014, p. 55.

${ }^{10}$ BRASIL. Lei $n^{\circ} 13.105$ de 16 de março de 2015. Dispõe sobre O Código de Processo Civil. In: Diário Oficial da República Federativa do Brasil, Brasília, DF, 17 mar.2015. Disponível em: < http://www.planalto.gov.br/ccivil_03/_ato2015-2018/2015/lei/l13105.htm> Acesso em: 26 abr. 2016, art. 334.

${ }^{11}$ Ibid., art. 334, $\$ 8^{\circ}$.

12 BRASIL. Ministério da Justiça. Escola Nacional de Mediação e Conciliação. Manual de mediação de conflito para advogados: escrito por advogados. Brasília: Ministério da Justiça, 2014, p. 38.
} 
Além disso, a atuação do mediador é regida por princípios fundamentais, conforme previsto no Art. $1^{\circ}$ do Código de Ética de Conciliadores e Mediadores Judiciais:

Artigo $1^{\circ}$ - São princípios fundamentais que regem a atuação de conciliadores e mediadores judiciais: confidencialidade, decisão informada, competência, imparcialidade, independência e autonomia, respeito à ordem pública e às leis vigentes, empoderamento e validação.

I - Confidencialidade - Dever de manter sigilo sobre todas as informações obtidas na sessão, salvo autorização expressa das partes, violação à ordem pública ou às leis vigentes, não podendo ser testemunha do caso, nem atuar como advogado dos envolvidos, em qualquer hipótese;

II - Decisão informada - Dever de manter o jurisdicionado plenamente informado quanto aos seus direitos e ao contexto fático no qual está inserido.

III - Competência - Dever de possuir qualificação que o habilite à atuação judicial, com capacitação na forma desta Resolução, observada a reciclagem periódica obrigatória para formação continuada;

IV - Imparcialidade - Dever de agir com ausência de favoritismo, preferência ou preconceito, assegurando que valores e conceitos pessoais não interfiram no resultado do trabalho, compreendendo a realidade dos envolvidos no conflito e jamais aceitando qualquer espécie de favor ou presente;

V - Independência e autonomia - Dever de atuar com liberdade, sem sofrer qualquer pressão interna ou externa, sendo permitido recusar, suspender ou interromper a sessão se ausentes as condições necessárias para seu bom desenvolvimento, tampouco havendo dever de redigir acordo ilegal ou inexequível;

$\mathrm{VI}$ - Respeito à ordem pública e às leis vigentes - Dever de velar para que eventual acordo entre os envolvidos não viole a ordem pública, nem contrarie as leis vigentes.

VII - Empoderamento - Dever de estimular os interessados a aprenderem a melhor resolverem seus conflitos futuros em função da experiência de justiça vivenciada na autocomposição.

VIII - Validação - Dever de estimular os interessados perceberem-se reciprocamente como serem humanos merecedores de atenção e respeito. ${ }^{13}$

Convém destacar que é dever do mediador contribuir para a criação de opções que superem a questão monetária, uma vez que é possível abordar/dialogar sobre assuntos que não estão diretamente ligados à disputa, mas que afetam a dinâmica dos mediandos (AZEVEDO, 2015, p.21). ${ }^{14}$

É fundamental que esse terceiro imparcial tenha a capacidade de escutar ativamente e de compreender os interesses, valores, necessidades e possibilidades presentes nas falas dos

${ }^{13}$ BRASIL. Resolução 125 de 29 de novembro de 2010. Dispõe sobre a Política Judiciária Nacional de tratamento adequado dos conflitos de interesses no âmbito do Poder Judiciário e dá outras providências. In: Conselho Nacional de Justiça, Brasília. DF, 19 nov. 2010. Disponível em: < http://www.cnj.jus.br/busca-atos-adm?documento=2579> Acesso em: 28 mar. 2016, anexo III, art. $1^{\circ}$.

${ }^{14}$ AZEVEDO, André Gomma de (Org.). Manual de mediação judicial. 5. ed. Brasília: CNJ, 2015. Disponível em: <http://www.cnj.jus.br/files/conteudo/destaques/ arquivo/2015/06/c276d2f56a76b701ca94df1ae0693f5b.pdf >. Acesso em: 21 jan. 2016, p. 21. 
mediados. Também é importante que tenha foco, sensibilidade e habilidade no manejo dos temas abordados. Além disso, a prática tem demonstrado que o desenvolvimento de uma boa percepção corporal voltada à identificação de questões é de extrema importância, porque por meio da linguagem corporal é possível identificar emoções não manifestas pelas palavras. ${ }^{15}$ Do mesmo modo:

Enquanto o juiz e o árbitro conduzem processos que tendem a se concluir pela adjudicação, o mediador oferece acolhimento, provoca empatia e convida à colaboração através do diálogo. [...] Não cabe ao mediador julgar, exercer juízos de valor ou auxiliar juridicamente as partes. Seu papel é de ajudar a entender melhor os problemas, aparando arestas e retirando obstáculos que impeçam a melhor solução para o caso concreto, a partir da compreensão efetiva do conflito em toda a sua extensão e complexidade. ${ }^{16}$

Por isso é que a utilização da teoria dos jogos pode contribuir para a prática da mediação. Esse ramo da economia pode oferecer aportes técnicos para os que pretendem compreender a dinâmica e métodos utilizados na mediação. A teoria dos jogos pode ajudar a entender o conflito, auxiliar na compreensão das possíveis estratégias de cada envolvido, bem como apontar caminhos para maximizar os ganhos dos mediandos, e, dessa forma, contribuir para o reestabelecimento do diálogo, para a pacificação das relações.

\section{A TEORIA DOS JOGOS NA MEDIAÇÃO}

O direito procura articular soluções não violentas para conflitos que possam surgir entre pessoas e definir as instituições que apontem soluções. Assim, para compreender o direito, é importante questionar e refletir sobre as interações entre os indivíduos em sociedade, sobre as fontes recorrentes de conflito e sobre as regras e instituições descobertas para prevenir sua eclosão. ${ }^{17}$ É nesse sentido que a teoria dos jogos pode auxiliar o direito, uma vez que seu objetivo é contribuir nas situações em que é necessário pensar estrategicamente.

A teoria dos jogos, portanto:

\footnotetext{
${ }^{15}$ BRASIL. Ministério da Justiça. Escola Nacional de Mediação e Conciliação. Manual de mediação de conflito para advogados: escrito por advogados. Brasília: Ministério da Justiça, 2014, p. 68.

${ }^{16}$ Ibid., p. 62.

${ }^{17}$ MACKAAY, Ejan; ROUSSEAU, Stéphane. Análise Econômica do Direito. Tradução de Rachel Sztajn. 2. ed. São Paulo: Atlas, 2015, p. 43.
} 
Apesar de ter surgido com objetivos essencialmente militares, contudo, a teoria dos jogos se aplica a muitas outras áreas do conhecimento humano, dentre elas a Biologia, a Genética, a Física e as Ciências Sociais. Em linhas gerais ela é considerada uma análise matemática de qualquer situação que envolva um conflito de interesses coma finalidade de encontrar as melhores opções, que associadas a determinadas condições, devem conduzir ao objetivo desejado por um jogador racional. ${ }^{18}$

Surgida no século XX, mais precisamente após a Primeira Guerra Mundial, a teoria dos jogos passou a ser desenvolvida com o intuito de tornar possível a previsão das estratégias de cada participante durante um jogo. Assim:

A teoria dos jogos consiste em um dos ramos da matemática aplicada e da economia que estuda situações estratégicas em que participantes se engajam em um processo de análise de decisões baseando sua conduta na expectativa de comportamento da pessoa com quem se interage. ${ }^{19}$

Por meio do comportamento estratégico, é possível perceber o ponto de vista do oponente e, desse modo, deduzir de que forma ele provavelmente reagirá a suas ações. A partir previsão das possíveis estratégias do adversário em um jogo, o outro jogador poderá definir sua tática e buscar o melhor resultado possível naquela interação. Dessa forma, acredita-se que: "Para se comportar estrategicamente cada jogador precisa tentar saber o que o outro jogador provavelmente fará. [...] A decisão que toma um dos jogadores depende do que ele pensa sobre como o outro jogador reagirá". ${ }^{20}$

Ainda de acordo com Pindyck e Rubinfeld:

Isso pode parecer óbvio, pois é claro que cada um deve compreender o ponto de vista de seu oponente. Entretanto, mesmo em situações simples de jogos, as pessoas frequentemente ignoram ou interpretam mal as posições dos oponentes, assim como as resposta racionais que delas decorrem. ${ }^{21}$

\footnotetext{
${ }^{18}$ SENGLER, Fabiana Marion; SPENGLER NETO, Theobaldo. A possibilidade do tratamento de conflitos no âmbito do Judiciário por meio da teoria dos jogos. Desenvolvimento em Questão, Ijuí: Editora Unijuí,v. 7, 2009, p. 75.

${ }_{19}$ AZEVEDO, André Gomma de (Org.). Manual de mediação judicial. 5. ed. Brasília: CNJ, 2015. Disponível em:

<http://www.cnj.jus.br/files/conteudo/destaques/arquivo/2015/06/c276d2f56a76b701ca94df1ae0693f5b .pdf >. Acesso em: 21 jan. 2016, p. 55.

20 STIGLITZ, Joseph E.; WALSH, Carl E. Introdução à economia.Tradução Helena Hoffmann. 3. ed. Rio de Janeiro: Campus, 2003, p. 322.

${ }^{21}$ PINDYCK, Robert S.; RUBINFELD, Daniel L. Microeconomia.Tradução Eleutério Prado, Thelma Guimarães e Luciana do Amaral Teixeira. 7. ed. São Paulo: Pearson, 2010, p. 426-427.
} 
Essa teoria caracteriza-se por ser uma ferramenta capaz de auxiliar a compreender ou prever os resultados possíveis que podem ocorrer nas diversas situações em que houver interação estratégica. ${ }^{22} \mathrm{Em}$ outras palavras, a teoria dos jogos consiste-se no estudo da tomada de decisões, em que as ações de um participante afetam não só seus ganhos e perdas como também os outros jogadores. Caracteriza-se como uma ferramenta utilizada para entender o comportamento racional estratégico. Nesse sentido:

Decisões estratégicas resultam em payoffs para os jogadores: resultados que acarretam recompensas ou benefícios. [...] Um objetivo crucial da teoria dos jogos é determinar a estratégia ótima para cada jogador. Estratégia é uma regra ou plano de ação para o jogo. [...]

A estratégia ótima para um jogador é aquela que maximiza o payoff esperado. ${ }^{23}$

As regras que guiam a interação estratégica e os possíveis resultados dessa relação constituem o que se costuma chamar de jogo. A descrição de um jogo será completa quando as ações que podem ser tomadas individualmente pelo jogador (comumente denominado de possíveis estratégias) e os possíveis resultados advindos dessa combinação (também conhecidos como prêmios ou payoffs do jogo) estiverem todos descritos. ${ }^{24}$ Há várias maneiras de representar as possíveis estratégias e os payoffs, uma bastante utilizada é a representação matricial de jogo.

O dilema do prisioneiro é um exemplo comumente empregado pelos pesquisadores para explicar a teoria dos jogos. O estudo desse jogo é importante para compreender por que algumas vezes os agentes econômicos não colaboram visando melhorar a situação de todos. Ele consiste na seguinte situação:

Dois prisioneiros, A e B, são acusados de colaborar em um crime. Depois de presos, eles são postos em celas separadas. Um policial vai a cada um deles e avisa: 'A situação é a seguinte. Se o seu parceiro confessa e você permanece em silêncio, você vai pegar cinco anos de cadeia. Mas se o seu parceiro confessa e você também confessa, vocês dois pegarão apenas três anos. Por outro lado, se tanto você como seu parceiro permanecerem em silêncio, nós poderemos dar uma pena menor, e você terá um ano de cadeia. Mas se o seu parceiro silencia e você confessa, nós soltaremos você em três meses.' Essa proposta é oferecida a ambos os prisioneiros. ${ }^{25}$

\footnotetext{
22 DE VASCONCELOS, Marco Antonio Sandoval; DE OLIVEIRA, Roberto Guena; BARBIERI, Fabio. Manual de microeconomia.3. ed. São Paulo: Atlas, 2011, p. 242.

${ }^{23}$ PINDYCK, Robert S.; RUBINFELD, Daniel L. Microeconomia.Tradução Eleutério Prado, Thelma Guimarães e Luciana do Amaral Teixeira. 7. ed. São Paulo: Pearson, 2010, p. 425-426, grifos do autor.

${ }^{24}$ DE VASCONCELOS, Marco Antonio Sandoval; DE OLIVEIRA, Roberto Guena; BARBIERI, Fabio. Manual de microeconomia.3. ed. São Paulo: Atlas, 2011, p. 239-240.

${ }^{25}$ STIGLITZ, Joseph E.; WALSH, Carl E. Introdução à economia.Tradução Helena Hoffmann. 3. ed. Rio de Janeiro: Campus, 2003, p. 322.
} 
Por meio do estudo desse simples jogo de interações estratégicas é possível perceber a estratégia ótima, a estratégia dominante, o equilíbrio de Nash, e, dessa forma, compreender a dinâmica da teoria dos jogos. Para tanto, é importante analisar a matriz de ganhos do jogo envolvendo o dilema do prisioneiro; esse diagrama exemplifica o que cada jogador pode ganhar ou perder numa interação.

Figura 1 - 0 jogo do dilema do prisioneiro

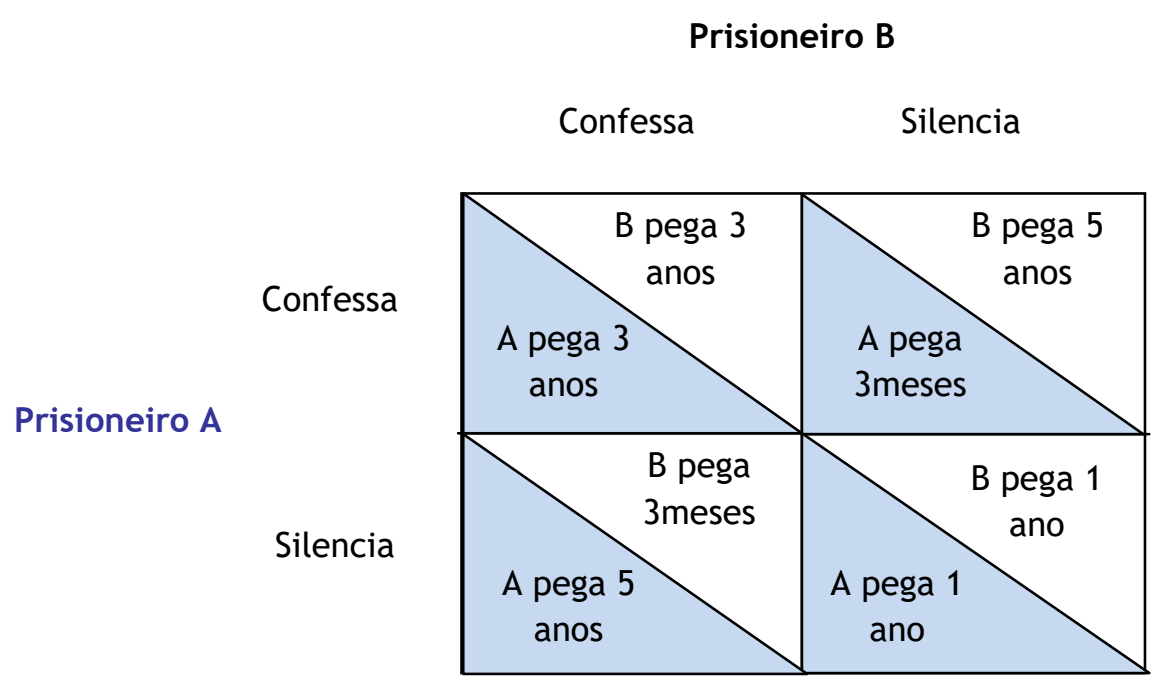

Fonte: STIGLITZ, Joseph E.; WALSH, Carl E. Introdução à economia.Tradução Helena Hoffmann. 3. ed. Rio de Janeiro: Campus, 2003, p. 322.

Convém dizer que a estratégia ótima é aquela que apresenta o melhor resultado possível para um dos participantes. No caso do dilema do prisioneiro, o resultado ótimo para o prisioneiro A ocorrerá se ele confessar e o prisioneiro B silenciar, pois nessa situação ele terá que cumprir apenas três meses de prisão (conforme primeiro quadro da segunda linha da matriz); nesse caso, a estratégia ótima para o prisioneiro A acarreta na obtenção do pior resultado pelo prisioneiro $B$, e vice-versa.

É importante saber identificar a estratégia ótima em um jogo, porque, muitas vezes, pode ser esse o resultado pretendido por um dos jogadores. Perceber isso pode ser decisivo também na tomada de decisão do jogador oponente. 
Já a estratégia dominante consiste na melhor estratégia para um jogador, independentemente de qual seja a estratégia adotada pelo outro. ${ }^{26}$ Caracteriza-se na ação que acarretará no melhor resultado para uma participante, embora a ação de seu oponente possa interferir no resultado, sempre será o melhor para aquele jogador quando se tratar da estratégia dominante.

Nesse sentido, retomando o dilema do prisioneiro, convém frisar que a estratégia dominante para os dois participantes é silenciar. Isso porque é de se supor que os jogadores irão raciocinar da seguinte forma: para cada escolha que eu possa fazer, qual é a melhor escolha para o outro jogador? Ao analisar o dilema do prisioneiro, deve-se indagar qual será a melhor estratégia do prisioneiro $B$, caso o prisioneiro A silenciar? Analisando a matriz de ganhos, verifica-se que a melhor estratégia para $B$, nessa hipótese, é confessar, pois assim deverá cumprir apenas três meses.

Entretanto, deve-se atentar que a teoria dos jogos pode ser analisada pelos dois participantes, de modo que o participante A poderá também perceber isso, ou seja, que a melhor alternativa para B é aquela na qual resultará na pena de três meses. Acontece que para o prisioneiro $B$ receber apenas a pena de três meses, o prisioneiro A deverá receber a pena de cinco anos, a qual é a maior sanção aplicável nesse caso. Sabendo disso, o prisioneiro A perceberá que a melhor estratégia para ele é também confessar.

Assim, conforme se observa no diagrama acima, se ambos os jogadores confessarem, a pena deles será de três anos. Por outro lado, se ambos silenciarem, a pena deles será apenas de um ano. 0 problema é que nesse jogo a estratégia ótima não é aquela em que ambos silenciam, mas ocorre quando apenas um silencia e o outro confessa. Caso os jogadores pudessem conversar e combinar que ambos iriam silenciar, a probabilidade de um deles descumprir com o acordo (por meio da confissão) seria grande, uma vez que assim ele atingiria o seu resultado ótimo. Por isso, que no dilema do prisioneiro o resultado dominante é aquele em que ambos confessam, embora isso não acarrete no resultado ótimo.

O dilema do prisioneiro é um jogo simples em que ambas as partes terminam em situação pior em virtude de cada uma seguir independentemente seu interesse próprio. Ambos ficariam em situação melhor se pudessem concordar sobre uma história e ter uma ameaça recíproca para evitar que o outro fuja da história. ${ }^{27}$

\footnotetext{
${ }^{26}$ DE VASCONCELOS, Marco Antonio Sandoval; DE OLIVEIRA, Roberto Guena; BARBIERI, Fabio. Manual de microeconomia.3. ed. São Paulo: Atlas, 2011, p. 243.

${ }^{27}$ STIGLITZ, Joseph E.; WALSH, Carl E. Introdução à economia.Tradução Helena Hoffmann. 3. ed. Rio de Janeiro: Campus, 2003, p. 322.
} 
Além disso, é interessante compreender no que consiste o equilíbrio de Nash. Desenvolvida pelo matemático John Nash, essa teoria surgiu com o intuito de nivelar os ganhos entre os participantes de um jogo, pois por meio de seus estudos percebe-se que:

A ideia de cooperação não seria totalmente incompatível com o pensamento de ganho individual, já que, para Nash, a cooperação traz a noção de que é possível maximizar ganhos individuais cooperando com o outro participante (até então, adversário). Não se trata de uma noção ingênua, pois, em vez de introduzir somente o elemento cooperativo, traz dois ângulos sob os quais o jogador deve pensar ao formular sua estratégia: o individual e o coletivo. 'Se todos fizerem o melhor para si e para os outros, todos ganham'. ${ }^{28}$

Dessa forma, o equilíbrio de Nash é um conjunto de ações em que cada jogador faz o melhor que pode em função das ações dos oponentes. Tais ações são estáveis quando não há estímulos para cada jogador se desviar de seu equilíbrio de Nash. ${ }^{29}$ Pode-se dizer que a teoria de Nash pretende colaborar para a dinâmica da teoria dos jogos por meio de uma tática altruísta, pois objetiva a reciprocidade de estratégias em prol do melhor resultado para ambos os jogadores.

Estratégias dominantes: eu estou fazendo o melhor que posso, independentementedo que você esteja fazendo. Você está fazendo o melhor que pode, independentemente do que eu esteja fazendo.

Equilíbrio de Nash: eu estou fazendo o melhor que posso em função daquilo que você está fazendo. Você está fazendo o melhor que pode em função daquilo que eu estou fazendo. ${ }^{30}$

Nesse contexto, há equilíbrio de Nash no dilema do prisioneiro naquela estratégia em que ambos silenciam ou quando ambos confessam, uma vez que o resultado obtido pelos dois prisioneiros será o mesmo em ambas as circunstâncias. Insta frisar que na primeira situação (quando ambos silenciam) além de haver o equilíbrio de Nash também há um resultado ótimo. Na segunda situação (ambos confessam) há o equilíbrio e a estratégia dominante.

De tal análise pode-se concluir que nem todo equilíbrio de Nash resultará no resultado ótimo; além disso, verifica-se "que todo equilíbrio em estratégias dominantes é um equilíbrio de Nash, embora nem todo equilíbrio de Nash seja equilíbrio em estratégias dominantes". ${ }^{31}$

\footnotetext{
${ }^{28}$ AZEVEDO, André Gomma de (Org.). Manual de mediação judicial. 5. ed. Brasília: CNJ, 2015. Disponível em:

<http://www.cnj.jus.br/files/conteudo/destaques/arquivo/2015/06/c276d2f56a76b701ca94df1ae0693f5b .pdf >. Acesso em: 21 jan. 2016, p. 56.

${ }^{29}$ PINDYCK, Robert S.; RUBINFELD, Daniel L. Microeconomia.Tradução Eleutério Prado, Thelma Guimarães e Luciana do Amaral Teixeira. 7. ed. São Paulo: Pearson, 2010, p. 429.

${ }^{30}$ Ibid., p. 430, grifos do autor.
} 
Mas o que as ideias envolvendo estratégia ótima, estratégia dominante e equilíbrio de Nash podem contribuir para a mediação? As contribuições da utilização dessas teorias durante o processo de mediação podem se revelar positivas. Isso porque o objetivo da mediação é reestabelecer o diálogo entre os envolvidos em um conflito, dessa forma, perceber as possíveis estratégias e ganhos pode auxiliar na utilização dos mecanismos necessários para reconstruir a relação rompida.

Para que isso seja possível é necessário que os envolvidos em um problema tenham tido alguma relação (só é possível reconstruir algo que já existiu), que eles estejam dispostos a mediar e que obtenham algum benefício com esse procedimento. A teoria dos jogos, sobretudo o equilíbrio de Nash, pode ajudar nesse sentido, pois:

[...] equilíbrio é um par de estratégias em que cada uma é a melhor resposta à outra: é o ponto em que, dadas as estratégias escolhidas, nenhum dos jogadores se arrepende, ou seja, não teria incentivo para mudar de estratégia caso jogasse novamente.

O princípio do equilíbrio proposto por Nash é, dentro dos pressupostos anteriormente mencionados, aquele de maior aplicação na composição e resolução de conflitos. ${ }^{32}$

Nas primeiras sessões de mediação, o mediador irá ouvir os mediandos de modo a perceber os principais anseios e frustrações decorrentes daquele conflito em questão. Dessa forma, o mediador poderá utilizar a teoria dos jogos para identificar as possíveis alternativas para o tratamento daquele caso, além disso, ao constatar as prováveis estratégias de cada mediando, o mediador também poderá identificar as estratégias "ótima" e "dominante".

Na sequência, esse terceiro imparcial poderá vislumbrar o equilíbrio de Nash por meio do estudo da matriz de ganhos daquele conflito/jogo. Verificar isso é interessante porque durante o desenvolvimento das sessões de mediação há uma fase na qual os mediandos buscam encontrar possíveis soluções para o problema. Nessa fase, o mediador pode auxiliar na percepção desses possíveis resultados.

Insta ressaltar que não compete ao mediador sugerir nenhuma resolução do conflito, sua função é facilitar o diálogo e apontar os caminhos, de maneira imparcial. Além disso, não é

${ }^{31}$ DE VASCONCELOS, Marco Antonio Sandoval; DE OLIVEIRA, Roberto Guena; BARBIERI, Fabio. Manual de microeconomia.3. ed. São Paulo: Atlas, 2011, p. 248.

32 SENGLER, Fabiana Marion; SPENGLER NETO, Theobaldo. A possibilidade do tratamento de conflitos no âmbito do Judiciário por meio da teoria dos jogos. Desenvolvimento em Questão, ljuí: Editora Unijuí,v. 7, 2009, p. 79. 
demais ressaltar que nem sempre a mediação resultará em um acordo, nem sempre colocará fim ao conflito, embora esse seja o objetivo almejado.

Considerando que a mediação busca o tratamento do conflito com vistas à satisfação por parte de todos os envolvidos, perceber o equilíbrio de Nash em um conflito pode se revelar como uma peça chave na pacificação das relações. Nesse sentido, Spengler refere que esse é um dos papéis do mediador, conforme segue:

Ouvindo e investigando cuidadosamente, o terceiro pode, muitas vezes, descobrir as aspirações e expectativas de cada lado e perceber o quão rigidamente fixadas estão. 0 terceiro pode usar seu conhecimento e sua autoridade para tentar refrear aspirações irreais. Ele pode com frequência ir além disso para fazer sugestões de acordos potenciais que possam ser aceitáveis a ambos os lados. ${ }^{33}$

A fim de elucidar melhor essa situação, é interessante trazer um exemplo hipotético (convém atentar que não há relação com nenhum caso real em específico), que consiste na seguinte situação: João e Maria conviveram durante anos em união estável e desse relacionamento nasceu Pedro. Após o nascimento de Pedro, os três se mudaram, passando a residir com a avó materna de Pedro. Acontece que nos últimos anos João e Maria começaram a se desentender, tornando a vida conjugal inviável. Assim, eles decidiram dissolver a união estável. Ocorre que Pedro é menor de idade, de modo que seus genitores passaram a brigar pela guarda da criança. Convém também informar, que nessa situação hipotética, os dois genitores têm condições (financeiras e psicológicas) para educar o menor.

Após algumas discussões, o ex-casal decidiu que a melhor opção seria tentar resolver esse conflito por intermédio da mediação, em vez de apelar imediatamente ao Poder Judiciário, eles entenderam que seria mais benéfico tentar evitar o ajuizamento de uma ação de guarda, pois poderia prejudicar o menor, Pedro. Dessa forma, nas primeiras sessões, a mediadora escolhida por João e Maria ouviu cada um, de modo a compreender o conflito bem como perceber as possíveis soluções almejadas pelos envolvidos.

Após ouvir os mediandos, verificou-se que nessa situação ${ }^{34}$ há as seguintes alternativas para resolução do conflito: a) João e Maria compartilham a guarda de Pedro; b) João cede a guarda a Maria; c) Maria cede a guarda a João;d) Ambos cedem a guarda à avó materna. A situação é apresentada na matriz a seguir (Figura 2):

\footnotetext{
${ }^{33}$ SPENGLER, Fabiana Marion. Retalhos da mediação. Santa Cruz do Sul: Esserenel Mondo, 2014, p. 54.

${ }^{34} \mathrm{Em}$ situações reais pode haver outras possíveis estratégias e resultados em virtude da problemática de cada caso.
} 
Figura 2 - Jogo da guarda de Pedro

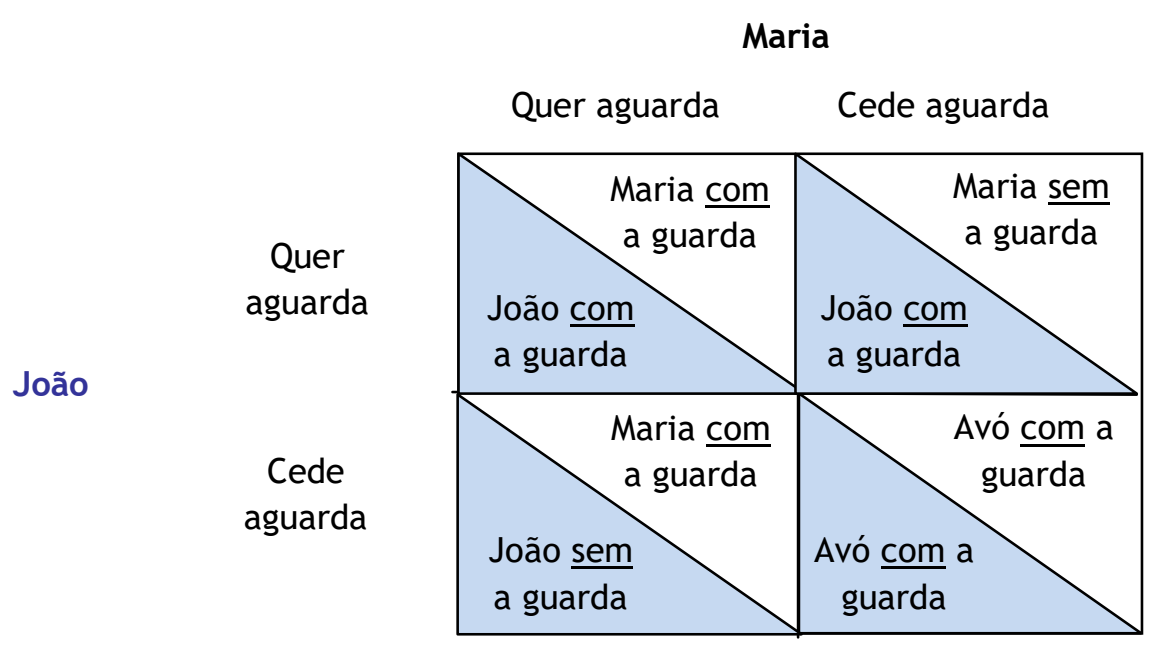

Da análise desse diagrama, pode-se concluir que: a estratégia dominante para Maria é ficar com a guarda de Pedro, haja vista que ela possui condições de criar o menor. A mesma estratégia é percebida para João. Além disso, para Pedro (o principal afetado nesse conflito) ficar com seus genitores é mais benefício do que com apenas um (Maria ou João) ou com nenhum (nesse caso ficar com a avó).

Portanto, após analisar a estratégia dominante, pode-se constatar que o resultado ótimo e o equilíbrio de Nash são os mesmos nesse simples exemplo, ou seja: a solução mais adequada para essa situação hipotética é que a guarda de Pedro seja compartilhada entre seus genitores.

É importante reforçar que a situação ora trazida busca apenas demonstrar como a teoria dos jogos pode ser aplicada durante as sessões de mediação. O exemplo é simples, diferentemente de situações reais, uma vez que esses casos, geralmente, envolvem questões muito mais complexas, podem apresentar mais estratégias/ações aos envolvidos, de modo que precisam ser estudadas de maneira muito mais atenta e cuidadosa.

Existem situações em que as possíveis estratégias e resultados não são percebidos com tanta facilidade, uma vez que podem envolver outros complexos dilemas sentimentais. Em situações como essas, o mediador poderá utilizar, além de estratégias puras, as estratégias mistas, que podem ser distinguidas da seguinte forma: 
Estratégias puras: estratégias em que os jogadores fazem as escolhas específicas ou agem de uma forma específica.

Estratégias mistas: estratégias nas quais os jogadores fazem escolhas aleatórias entre duas ou mais ações possíveis, com base em um conjunto de probabilidades escolhidas. ${ }^{35}$

As estratégias mistas podem contribuir para o equilíbrio de Nash, uma vez que ajuda na escolha das probabilidades que cada jogador atribui às diferentes estratégias que the são disponíveis para os jogos que não apresentam equilíbrio de Nash em estratégias puras. ${ }^{36}$ Dessa forma, percebe-se que as estratégias mistas possibilitam soluções para jogos mesmo quando as puras falham. No entanto, é importante atentar que as soluções envolvendo estratégias mistas serão consideradas razoáveis dependendo do jogo específico ou dos jogadores. ${ }^{37}$

Em outras palavras: em alguns casos, utilizar estratégias mistas pode se revelar mais benéfico no tratamento de conflito, é possível que elas contribuam para encontrar o equilíbrio de Nash. Assim, tanto as estratégias puras, quanto as mistas podem auxiliar na mediação, sua utilização dependerá da análise do caso concreto.

\section{CONCLUSÃO}

Por meio do estudo desenvolvido, verificou-se a relevância da teoria dos jogos para a prática da mediação, principalmente para o mediador. Além disso, percebeu-se que a compreensão das concepções de estratégia ótima, estratégia dominante e equilíbrio de Nash auxiliam o mediador a vislumbrar as possíveis ações e ganhos durante o procedimento da mediação. Isto porque quando se verifica as possibilidades dos participantes agirem de determinadas maneiras, fica mais fácil elaborar estratégias e, assim, reestabelecer o diálogo.

A teoria dos jogos pode a equilibrar os anseios dos mediandos, aumentar a probabilidade de pacificar a relação até então rompida. Entretanto, há muito o que se estudar sobre o comportamento estratégico na mediação. Este trabalho buscou trazer os principais conceitos envolvendo a mediação e a teoria dos jogos, sem, contudo, ter a pretensão de esgotar esses complexos temas.

\footnotetext{
${ }^{35}$ PINDYCK, Robert S.; RUBINFELD, Daniel L. Microeconomia.Tradução Eleutério Prado, Thelma Guimarães e Luciana do Amaral Teixeira. 7. ed. São Paulo: Pearson, 2010, p. 433.

${ }^{36}$ DE VASCONCELOS, Marco Antonio Sandoval; DE OLIVEIRA, Roberto Guena; BARBIERI, Fabio. Manual de microeconomia.3. ed. São Paulo: Atlas, 2011, p. 251.

${ }^{37}$ PINDYCK, Robert S.; RUBINFELD, Daniel L. Microeconomia.Tradução Eleutério Prado, Thelma Guimarães e Luciana do Amaral Teixeira. 7. ed. São Paulo: Pearson, 2010, p. 433.
} 


\section{REFERÊNCIAS}

AZEVEDO, André Gomma de (Org.). Manual de mediação judicial. 5. ed. Brasília: CNJ, 2015. Disponível em:

<http://www.cnj.jus.br/files/conteudo/destaques/arquivo/2015/06/c276d2f56a76b701ca94df1 ae0693f5b.pdf >. Acesso em: 21 jan. 2016.

BRASIL. Ministério da Justiça. Escola Nacional de Mediação e Conciliação. Manual de mediação de conflito para advogados: escrito por advogados. Brasília: Ministério da Justiça, 2014.

BRASIL. Resolução 125 de 29 de novembro de 2010. Dispõe sobre a Política Judiciária Nacional de tratamento adequado dos conflitos de interesses no âmbito do Poder Judiciário e dá outras providências. In: Conselho Nacional de Justiça, Brasília. DF, 19 nov. 2010. Disponível em: < http://www.cnj.jus.br/busca-atos-adm?documento=2579> Acesso em: 28 mar. 2016.

BRASIL. Lei nº 13.105 de 16 de março de 2015. Dispõe sobre o Código de Processo Civil. In: Diário Oficial da República Federativa do Brasil, Brasília, DF, 17 mar.2015. Disponível em: <

http://www.planalto.gov.br/ccivil_03/_ato2015-2018/2015/lei/l13105.htm> Acesso em: 26 abr. 2016.

DE VASCONCELOS, Marco Antonio Sandoval; DE OLIVEIRA, Roberto Guena; BARBIERI, Fabio. Manual de microeconomia.3. ed. São Paulo: Atlas, 2011.

MACKAAY, Ejan; ROUSSEAU, Stéphane. Análise Econômica do Direito. Tradução de Rachel Sztajn. 2. ed. São Paulo: Atlas, 2015.

MORAIS, Luiz Bolzan de; SPENGLER, Fabiana Marion. Mediação e arbitragem: alternativas à jurisdição.3. ed. Porto Alegre: Livraria do Advogado, 2012.

MULLER, Jean-Marie. 0 princípio da não-violência: uma trajetória filosófica. Tradução Inês Polegato. São Paulo: Palas Athena, 2007.

PINDYCK, Robert S.; RUBINFELD, Daniel L. Microeconomia.Tradução Eleutério Prado, Thelma Guimarães e Luciana do Amaral Teixeira. 7. ed. São Paulo: Pearson, 2010.

SPENGLER, Fabiana Marion. Retalhos da mediação. Santa Cruz do Sul: Esserenel Mondo, 2014. SENGLER, Fabiana Marion; SPENGLER NETO, Theobaldo. A possibilidade do tratamento de conflitos no âmbito do Judiciário por meio da teoria dos jogos. Desenvolvimento em Questão, ljuí: Editora Unijuí,v. 7, p. 63-86, 2009.

STIGLITZ, Joseph E.; WALSH, Carl E. Introdução à economia.Tradução Helena Hoffmann. 3. ed. Rio de Janeiro: Campus, 2003.

WARAT, Luis Alberto. Surfando na pororoca: o ofício do mediador. Florianópolis: Fundação Boieteux, 2004.v. III.

Recebido em: 27/04/2016 / Aprovado em: 02/08/2016 